Acta Cryst. (1986). A42, 80

\section{Union Sponsorship and Financial Support for International Meetings}

Organisers of international meetings and schools are invited to seek sponsorship and financial support from the International Union of Crystallography.

The procedure to be followed is that the organisers should request the appropriate questionnaire from the Chairman of the IUCr Calendar Sub-Committee (Professor M. Nardelli, Instituto di Chimica Generale ed Inorganica, Università di Parma, Via M. D'Azeglio 85, 43100 Parma, Italy) to whom it should be returned. This Sub-Committee makes its recommendation to the IUCr Executive Committee, which takes the final decision. This procedure takes not less than three months and therefore application should be made as early as possible.

In making an application for sponsorship, the meeting organisers should emphasise the international character of the meeting and give guarantees about the attendance of bona fide scientists from all countries. In addition to normal financial support for these meetings there is the possibility of extra finance to assist the attendance of young scientists.

The Union publishes a Calendar of Meetings in its journal, the Journal of Applied Crystallography. Notices of new meetings for inclusion in this list, giving the dates, location and title of the meetings, a few sentences describing the topics covered, and the name and address of the person from whom further information may be obtained, should be sent as soon as these details are known to Dr J. N. King, Executive Secretary, International Union of Crystallography, 5 Abbey Square, Chester $\mathrm{CH} 12 \mathrm{HU}$, England.

The questions asked in the Calendar Sub-Committee questionnaire are given below. It is most helpful if all these questions can be answered as fully as possible.

1. Dates and location

2. (a) Subject

(b) Last meeting with a similar programme

(c) Titles of Topics

(d) Titles of Invited Papers (if available)

3. (a) Names of local organisers

(b) Name and address of the individual to contact for information

4. (a) Expected budget total

(b) Origin of income

(c) Conference fee
5. Expected number of participants
(a) local
(b) non-local

6. Attendance is open by invitation

7. Do the authorities of the country in which the meeting is to take place guarantee free entrance of bona fide scientists from all countries?

8. Deadlines
(a) registration application
(b) paper submission

9. Is the proposal supported by

(a) the National Committee for Crystallography of the country?

(b) related IUCr Commission(s)? If so, which Commission(s)?

10. International character guaranteed by

(a) the composition of the International Programme Committee

(b) other arrangements

11. Amounts of financial support requested from IUCr, with indication of intended use, for

(a) travel and subsistence of young scientists

(b) other purposes

12. Is publication of proceedings intended?

The responsible editor (if appointed)

13. Additional information (on importance of the meeting, on factors taken into account in the planning, etc.)

\section{Notes and News}

Acta Cryst. (1986). A42, 80

\section{Journal of Materials Research}

Dr H. William Koch, Director of the American Institute of Physics (AIP) announced that AIP will publish the Journal of Materials Research for the Materials Research Society, a recently affiliated society of AIP. The new journal, to begin publication in January 1986, will be a broadly based review of scientific literature related to materials research. Dr Charles B. Duke of Xerox Corporation in Rochester, New York will serve as Editor-in-Chief. Research on Materials includes studies on the preparation, processing, characterization, and properties of materials. The journal will be distributed to members of the Materials Research Society as well as subscribers. 